\title{
Efeito do extrato de tiririca e bioestimulante no enraizamento de estacas de Hyptis marrubioides Epl.
}

Jéssica Azevedo Batista ${ }^{1}$

Priscila Pereira Botrel ${ }^{2}$

Felipe Campos Figueiredo ${ }^{3}$

\section{Resumo}

Hyptis marrubioides Epl. (hortelã-do-campo), é uma planta medicinal pertencente à família Lamiaceae, conhecida pela presença de óleos voláteis. Verifica-se uma tendência na utilização de reguladores vegetais para o enraizamento de estacas quando há necessidade de acelerar a propagação vegetativa ou no caso de espécies que apresentam difícil enraizamento, como é o caso da H. marrubioides. $O$ objetivo do presente trabalho foi avaliar diferentes concentrações do extrato de tubérculos de tiririca $(0,0 ; 25,0 \% ; 50,0 \%$ e $100,0 \%)$ e do Bioestimulante Radifarm ${ }^{\circledR}(0,0$ mL e 2,5 $\mathrm{mL}$ ). Foram conduzidos dois experimentos em delineamento experimental inteiramente casualizado (DIC), sendo, o primeiro, constituído por seis repetições por tratamento e cinco plantas por parcela e o segundo, com cinco repetições e 10 plantas por parcela. Após 40 dias, foram avaliados o comprimento de raízes $(\mathrm{cm})$, biomassa seca de raiz $(\mathrm{mg})$, número de nós, número de folhas, número de brotos, comprimento do broto $(\mathrm{cm})$, biomassa seca da parte aérea, porcentagem de enraizamento e teor de clorofila. Verificou-se diferença significativa nos tratamentos com extrato de tiririca apenas para a variável biomassa seca da parte aérea, observando-se uma relação dose-dependente. O Bioestimulante Radifarm ${ }^{\circledR}$ proporcionou maior número de nós em estacas herbáceas de $H$. marrubioides $(6,24)$ e teor de clorofila a $(189,4)$. Em relação à biomassa seca de raiz, o bioestimulante promoveu um acúmulo médio de 24,4 mg.

Palavras-chave: Hortelã-do-campo. Planta medicinal. Extrato de tiririca. Bioestimulante

\section{Introdução}

A família Lamiaceae é uma das famílias mais conhecidas e utilizadas popularmente, com potencial químico e rica em espécies aromáticas de grande importância econômica (SIMÕES; SPITZER, 2000).

Segundo Menezes (1994), a família Lamiaceae é relativamente bem estudada do ponto de vista químico. Com respeito ao metabolismo especial, apresenta uma grande variedade de classes de micromoléculas, existindo representantes da Via do Ácido Acético, da Via do Ácido Chiquímico e provenientes de biossíntese mista. Além disso, tem grande importância econômica por ser fonte de

\footnotetext{
1 Instituto Federal de Educação, Ciência e Tecnologia do Sul de Minas Gerais, Campus Muzambinho, Bióloga. Muzambinho, Minas Gerais, Brasil. jessikbio@hotmail.com. (35) 3571 - 5051. Estrada de Muzambinho, Km 35 - Bairro Morro Preto, Cx. Postal 02, CEP 37890-000.

2 Instituto Federal de Educação, Ciência e Tecnologia do Sul de Minas Gerais, Campus Muzambinho, professora pesquisadora. Muzambinho, Minas Gerais, Brasil. priscila.botrel@muz.ifsuldeminas.edu.br. (35) 3571 - 5051. Estrada de Muzambinho, Km 35 - Bairro Morro Preto, Cx. Postal 02, CEP 37890-000.

3 Instituto Federal de Educação, Ciência e Tecnologia do Sul de Minas Gerais, Campus Muzambinho, professor pesquisador. Muzambinho, Minas Gerais, Brasil. felipe.figueiredo@muz.ifsuldeminas.edu.br. (35) 3571 - 5051. Estrada de Muzambinho, Km 35 - Bairro Morro Preto, Cx. Postal 02, CEP 37890-000.
} 
óleos essenciais. Muitas espécies são utilizadas como condimentos importantes em culinária, sendo apreciadas pelo aroma ou pelo sabor que comunicam aos alimentos.

O metabolismo especial das plantas do gênero Hyptis é de notável variabilidade, apresentando predominância de óleos essenciais, que têm muito valor junto a diversas comunidades que as usam pelas propriedades terapêuticas. Falcão e Menezes (2003) citam 25 espécies desse gênero estudadas sob o aspecto farmacológico, descrevendo a presença de substâncias com atividades antimicrobiana, antifúngica, citotóxica, anti-inflamatória, anti-HIV e inseticida.

Hyptis marrubioides (hortelã-do-campo) é uma espécie conhecida pelas suas atividades contra infecções gastrointestinais, infecções de pele, dores e câimbras (CORRÊA, 1931).

Muitos estudos foram realizados sobre essa espécie, dentre os quais se destacam os estudos de Sales et al. (2007), quando se estudaram os principais constituintes químicos presentes no óleo essencial de H. marrubioides, em duas localidades do Sul de Minas Gerais. Botrel (2009a) verificou que o óleo essencial dessa espécie apresentou efeito tóxico sobre a formiga cortadeira (Atta sexdens rubropilosa FOREL); em outro trabalho, Botrel et al. (2009b) estudaram a composição química do óleo essencial extraído de inflorescências de genótipo roxo e branco.

A propagação dessa espécie se dá por meio de sementes, entretanto é necessário estudar outros meios de propagação para que se possam manter as características genéticas da planta doadora.

A produção por sementes apresenta grande variabilidade com relação à produção de metabólitos secundários, o que torna difícil o plantio uniforme de genótipos com alto poder de síntese desses metabólitos (PRADO et al., 2000).

Cita-se, dentre os métodos clássicos de propagação vegetativa, a estaquia, que surge como alternativa na reprodução de plantas medicinais e pode constituir-se em um método eficiente para multiplicação de $\mathrm{H}$. marrubioides. Por meio da estaquia, poderiam ser obtidas plantas uniformes quanto ao teor e ao rendimento de óleo essencial, selecionadas a partir de indivíduos superiores no campo.

A estaquia permite que se obtenha um grande número de mudas extraídas de poucas plantas-matrizes e exige um espaço relativamente pequeno; trata-se de uma técnica simples, que apresenta baixo custo e não requer treinamento especializado, como no caso da enxertia ou da micropropagação (HARTMANN et al., 2002).Para realização com sucesso da propagação via estaquia, às vezes é necessária aplicação exógena de auxinas, estimulando a emissão de raízes.

Cyperus rotundus é conhecida no Brasil como tiririca, planta daninha considerada a mais disseminada e agressiva de todo o mundo (CUDNEY, 1997). Estudos realizados avaliando o efeito de $C$. rotundus no enraizamento de estacas mostraram grandes resultados, como destacam vários trabalhos (CONCl et al., 2004); (SILVA, 2007); (NETO; SILVA, 2008); (XAVIER et al., 2009); (RODRIGUES et al., 2010), entre outros.

Além do uso de fitormônios, estudos estão sendo realizados sobre o uso de bioestimuladores no enraizamento de estacas. Pouco se sabe sobre o efeito fisiológico e as respostas dos bioestimulantes no método de propagação por estaquia, no entanto, sabe-se dos efeitos dos reguladores vegetais na fisiologia do desenvolvimento vegetal e dos prováveis efeitos sinérgicos da auxina (IBA), giberelina (GA3) e citocinina (CK) em atuação conjunta em diferentes culturas (CASTRO; VIEIRA, 2001). A aplicação de bioestimulantes tem apresentado resultados significativos no desenvolvimento e produtividade de diferentes espécies de plantas agrícolas, olerícolas e frutíferas (CASTRO; VIEIRA, 2004).

Portanto, diante da importância química da espécie em estudo - H. marrubioides - é necessária a investigação de métodos de propagação eficientes, com o objetivo de obter mudas com mesmo padrão e vigor. Por essa razão, o presente trabalho objetivou avaliar o efeito de diferentes concentra- 
ções de extratos aquosos de tubérculos de tiririca e do bioestimulante Radifarm ${ }^{\circledR}$ no enraizamento de estacas de $H$. marrubioides.

\section{Materiais e Métodos}

Foram desenvolvidos dois experimentos no período de março a maio de 2013, em Muzambinho, Minas Gerais, em casa de vegetação localizada no Setor de Jardinagem do IFSULDEMINAS.

\section{Experimento 1: Extrato de tiririca}

O material vegetal utilizado para fornecimento das estacas (plantas matrizes) para o experimento com extrato de Tiririca foi obtido de populações de plantas de H. marrubioides com seis meses de idade, cultivadas em casa de vegetação no Setor de Jardinagem do Instituto Federal do Sul de Minas, Campus Muzambinho. Realizou-se uma seleção dos indivíduos mais vigorosos no momento da coleta, realizada por volta das oito horas. Utilizaram-se estacas herbáceas, de aproximadamente sete centímetros, coletadas com auxílio de uma tesoura.

O delineamento experimental utilizado foi inteiramente casualizado constituído por quatro concentrações de extrato de tiririca $(0 \%, 25 \%, 50 \%$ e 100\%), com seis repetições por tratamento e cinco estacas por parcela.

Para obtenção dos extratos de $C$. rothundus, foram utilizados tubérculos frescos, coletados em lavoura de café localizada no Instituto Federal do Sul de Minas, Campus Muzambinho.

Após a coleta, os tubérculos foram lavados, secos com papel toalha e pesados. Foram utilizados $20 \mathrm{~g}$ de tubérculos para $400 \mathrm{~mL}$ de água destilada, sendo posteriormente triturados no liquidificador, peneirados e diluídos em água destilada, proporcionando as seguintes concentrações: 25\%, 50\%, $100 \%$ e Testemunha (água 100\%). Posteriormente, as bases das estacas foram mergulhadas por 30 segundos nos tratamentos, sendo 30 plântulas por tratamento, totalizando 120 estacas herbáceas de H. marrubioides.

Os dados observados foram submetidos à análise de variância, e as médias comparadas pelo teste de Scott-Knott ao nível de $6 \%$ de probabilidade, com auxílio do software SISVAR (FERREIRA, 2000).

\section{Experimento 2: Bioestimulante Radifarm ${ }^{\circledR}$}

As estacas foram obtidas de populações nativas de $H$. marrubioides, localizadas no campo, no município de Ribeirão Vermelho, situado a $21^{\circ} 12^{\prime} 49^{\prime \prime}$ de Latitude Sul e $45^{\circ} 01^{\prime} 10^{\prime \prime}$ de Longitude Oeste de Greenwich, a uma altitude de $806 \mathrm{~m}$.

0 delineamento experimental utilizado foi inteiramente casualizado, constituído por duas concentrações do Biostimulante Radifarm ${ }^{\circledR}(0,0$ e 2,5 ml/L), com cinco repetições por tratamento e 10 plantas por parcela. Foi realizada uma diluição de $2,5 \mathrm{~mL}$ do bioestimulante em 1 litro de água destilada.

Foram aplicados $2 \mathrm{~mL}$ da solução por célula da bandeja, diretamente no substrato areia. $\mathrm{Na}$ testemunha, aplicou-se apenas água destilada.

Quinze dias após a primeira aplicação, foi realizada uma segunda aplicação do bioestimulante, utilizando-se o mesmo procedimento inicial.

\section{Instalação dos experimentos e variáveis resposta}


Estacas do tipo herbáceas, com aproximadamente sete centímetros de comprimento, foram colocadas em bandejas de polipropileno expandido com 128 células contendo o substrato areia.

Após o plantio em bandejas, as estacas foram cobertas com plástico, proporcionando uma câmara úmida e, posteriormente, foram levadas para um telado com sombreamento de $50 \%$. A nebulização ocorreu, diariamente, com nebulizador manual.

As avaliações foram realizadas 40 dias após a instalação dos experimentos, quando as estacas foram retiradas e cuidadosamente lavadas em água corrente, para evitar a perda de raízes.

Foram avaliados o comprimento de raízes $(\mathrm{cm})$, a biomassa seca de raízes $(\mathrm{mg})$, o número de folhas por estaca, o número de brotos, o comprimento do broto, o número de nós, a biomassa seca da parte aérea (mg), a porcentagem de enraizamento e os teores de clorofila a, b e total.

As raízes foram secas em estufa de circulação forçada de ar a $40^{\circ} \mathrm{C}$ até manter o peso constante.

Nos dois experimentos, foi realizada análise dos teores de clorofila $a, b$ e total $(a+b)$, na primeira folha totalmente expandida da estaca (da base para o ápice), utilizando-se para tal um clorofilômetro marca ClorofiLOG ${ }^{\circledR}$, modelo CFL 1030, operado conforme instruções do fabricante (FALKER, 2008). Nesse aparelho, as unidades de mensuração são denominadas Índice de Clorofila Falker (ICF). Em cada folha, foram realizadas três leituras, no terço médio da lâmina, para se obter um valor médio.

\section{Resultados e Discussão}

\section{Experimento 1: Influência do extrato de tiririca no enraizamento de estacas de $\boldsymbol{H}$. marrubioides}

Estacas tratadas com extrato de tiririca apresentaram em média 96\% de enraizamento.

Houve diferença significativa para a variável biomassa seca da parte aérea. À medida que se aumenta a concentração do extrato de tiririca, aumenta-se a biomassa seca da parte aérea de estacas herbáceas de $H$. marrubioides (Figura 1 ).

A biomassa seca máxima (214,04 mg) foi alcançada ao utilizar $73,06 \%$ do extrato de tiririca em estacas herbáceas de $H$. marrubioides.

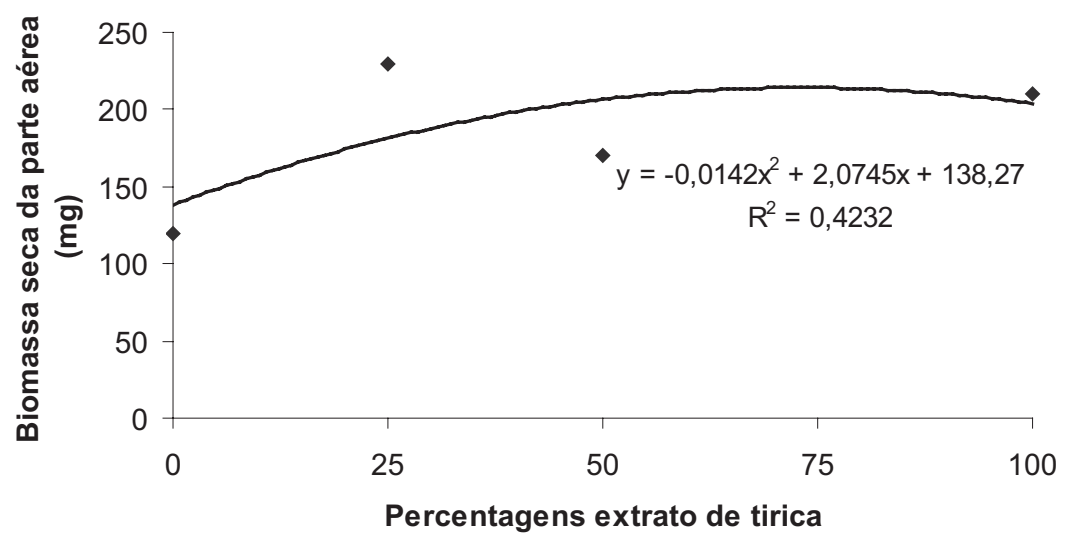

Figura 1 Biomassa seca da parte aérea de estacas de Hyptis marrubioides tratadas com diferentes percentagens de extrato de tiririca.

Fonte: elaboração dos autores. 
Para as demais variáveis analisadas, não houve diferença significativa.

Os teores de clorofila $a$, b e total não foram influenciados pela utilização de diferentes concentrações do extrato de tiririca (Figura 2).

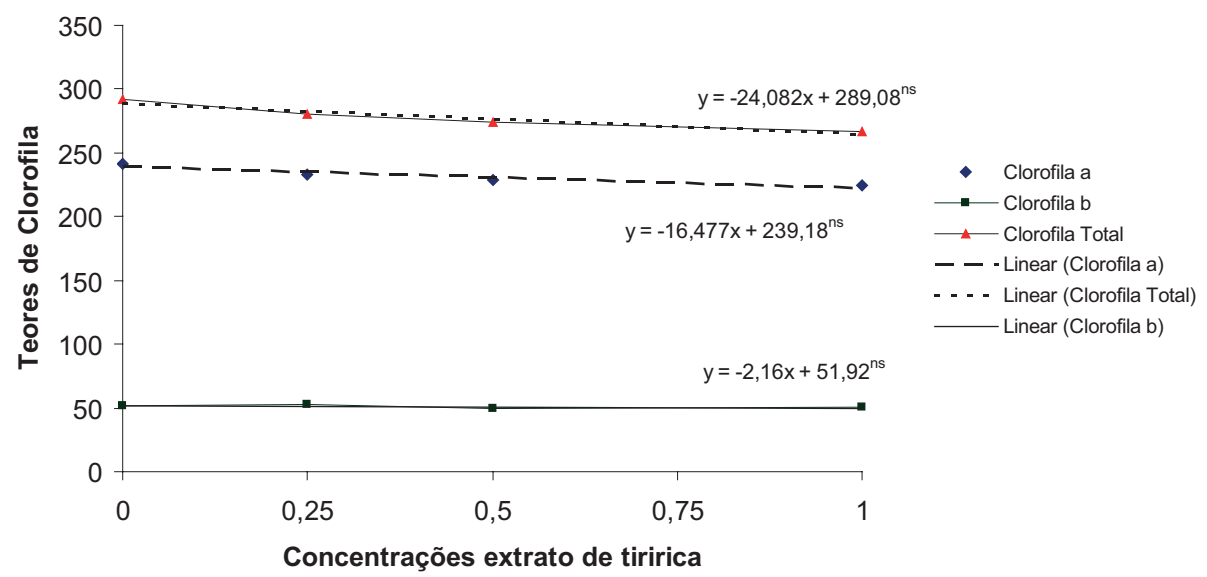

Figura 2 Teores médios de clorofila a, b e total em folhas de estacas herbáceas enraizadas de H. marrubioides, em função de diferentes concentrações de extrato de tiririca.

Fonte: Elaboração dos autores.

Neto e Silva (2008) avaliaram o efeito de diferentes concentrações de extratos aquosos de tiririca sobre o enraizamento de cana-de-açúcar (Saccharum spp.), verificando que, apesar de uma alta taxa de enraizamento, não houve diferença significativa entre os tratamentos. No entanto, para as variáveis número de raízes por estaca e tamanho das raízes todos os tratamentos diferiram entre si, apresentando uma relação dose-dependente, ou seja, quanto maior a concentração do extrato de tiririca, maiores as quantidades e medidas para essas variáveis.

Silva (2007), utilizando extrato de bulbos de tiririca, em estacas de pinhão-manso (Jatropha curcas L.), pôde verificar que esse extrato apresentou-se como um bom promotor no enraizamento das estacas, favorecendo também um bom desenvolvimento do comprimento das raízes.

Estudos realizados por Arruda et al. (2009), avaliando a atividade hormonal do extrato de tiririca na rizogênese de estacas de sapoti (Achras sapota L.), verificaram um aumento na sobrevivência e no enraizamento das estacas de sapotizeiro.

Fanti (2008), avaliando a aplicação de extratos de folhas e de tubérculos de tiririca em estacas de Duranta repens (L.), conhecida como pingo-de-ouro, observou que não houve diferença estatística dos reguladores vegetais utilizados no enraizamento de estacas. Resultados semelhantes foram encontrados no presente trabalho, pois não se observou diferença significativa para biomassa seca de raiz e comprimento de raiz $(\mathrm{cm})$. Entretanto, o tratamento com extrato de tiririca apresentou resultados significativos para biomassa seca da parte aérea em estacas herbáceas de $H$. marrubioides.

\section{Experimento 2: Influência do bioestimulante Radifarm ${ }^{\circledR}$ no enraizamento de estacas de $\boldsymbol{H}$. marrubioides}

O bioestimulante Radifarm ${ }^{\circledR}$ proporcionou $76 \%$ de enraizamento em estacas herbáceas de $H$. marrubioides, comparado a $64 \%$ de enraizamento obtido pela testemunha.

Houve diferença significativa apenas para as variáveis, número médio de nós e biomassa seca de raiz (mg). 0 bioestimulante Radifarm ${ }^{\circledR}$ proporcionou maior número de nós em estacas herbáceas 
de $H$. marrubioides $(6,24)$, comparado à testemunha $(5,26)$. Em relação à biomassa seca de raiz, 0 Bioestimulante promoveu um acúmulo médio de 24,4 mg (Tabela 1 e Figura 3).

Tabela1 Número médio de nós em estacas herbáceas de $H$. marrubioides submetidas a aplicação do Bioestimulante Radifarm ${ }^{\circledR}$.

\begin{tabular}{ll}
\hline Tratamentos & Número médio de nós \\
\cline { 2 - 2 } Testemunha & $5,26 \mathrm{~b}$ \\
Radifarm & $6,24 \mathrm{a}$ \\
\hline
\end{tabular}

As médias seguidas da mesma letra não diferem entre si pelo teste de Scott-Knott ao nível de $5 \%$ de probabilidade. Fonte: Elaboração dos autores.

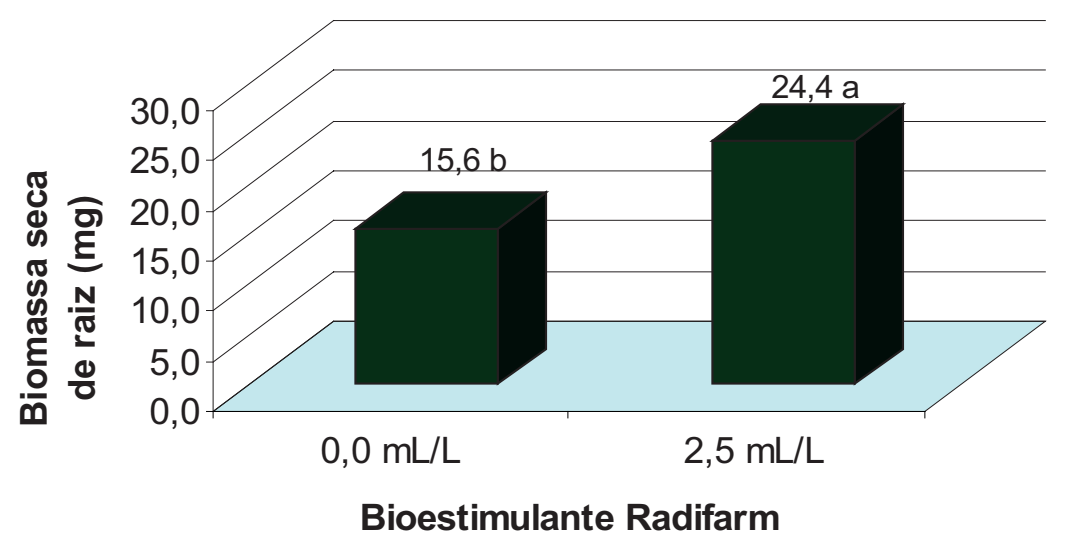

Figura 3 Biomassa seca de raiz $(\mathrm{mg})$ em estacas herbáceas de $H$. marrubioides submetidas a aplicação do Bioestimulante Radifarm ${ }^{\circledR}$.

As médias seguidas da mesma letra não diferem entre si pelo teste de Scott-Knott ao nível de 6\% de probabilidade. Fonte: Elaboração dos autores.

Assim como no presente estudo, Klahold (2005), avaliando a resposta da soja à ação do bioestimulante Stimulate ${ }^{\circledR}$, observou efeitos positivos sobre a massa seca da raiz.

Silva (2008), estudando o enraizamento de estacas de Pinheira (Annonas quamosa L.), Gravioleira (Annona muricata L.) e Atemoeira (Annona squamosa L. x Annona cherimola L.), verificou que o uso do bioestimulante Stimulate ${ }^{\circledR}$ não foi viável para o método de propagação por estaquia, contribuindo apenas na porcentagem de sobrevivência e massa de matéria seca das raízes.

Estudos realizados por Dias et al. (2012), analisando a ação do Bioestimulante Stimulate ${ }^{\circledR}$ e substratos na propagação da amoreira-preta, corroboram os resultados do presente trabalho, visto que não houve diferença significativa para o comprimento de raiz.

Pierezan et al. (2012), avaliando a emergência e o crescimento inicial de mudas de jatobá (Hymenaea courbari L.) tratadas com o bioestimulante vegetal Stimulate ${ }^{\circledR}$ e sob diferentes níveis de sombreamento, verificaram que, para altura e diâmetro, não houve interação entre os níveis de luz e doses de bioestimulante.

No presente estudo, não houve diferença significativa entre as concentrações do bioestimulante Radifarm ${ }^{\circledR}$ no comprimento de estacas de $H$. marrubioides. Houve diferença significativa para teores de clorofila a. 0 bioestimulante Radifarm ${ }^{\circledR}$ proporcionou maior teor de clorofila a $(189,4)$, comparado à testemunha $(151,6)$, o que provavelmente está relacionado com o aumento da taxa fotossintética. 
Tabela 2 Valores médios de clorofila a, b e total em função da aplicação do bioestimulante Radifarm ${ }^{\circledR}$.

\begin{tabular}{llll}
\hline Tratamento & Clorofila a & Clorofila b & Total a $+\mathrm{b}$ \\
\cline { 2 - 4 } Testemunha & $151,6 \mathrm{~b}$ & $33,1 \mathrm{a}$ & $184,7 \mathrm{a}$ \\
Radifarm & $189,4 \mathrm{a}$ & $38,6 \mathrm{a}$ & $203,5 \mathrm{a}$ \\
\hline
\end{tabular}

As médias seguidas da mesma letra na coluna não diferem entre si pelo teste de Scott-Knott ao nível de $6 \%$ de probabilidade.

Fonte: Elaboração dos autores.

A clorofila a é a principal responsável pela coloração verde das plantas e pela realização da fotossíntese (MEYER, 1974). Dessa forma, o aumento do teor da clorofila a possibilita o aumento da taxa fotossintética.

A clorofila $b$ é um pigmento que ajuda a ampliar a faixa de absorção de luz que pode ser usada na fotossíntese. A função dessa clorofila é auxiliar da clorofila a, transferindo a energia captada para as moléculas que realizarão a fotossíntese (RAVEN, 1983).

\section{Conclusão}

O extrato de tiririca não apresentou influência no enraizamento de estacas herbáceas de Hyptis marrubioides.

O Bioestimulante Radifarm ${ }^{\circledR}$ proporcionou maior número de nós em estacas herbáceas de $H$. marrubioides $(6,24)$, teor de clorofila a $(189,4)$, porcentagem de enraizamento $(76,0 \%)$ e biomassa seca de raiz $(24,4 \mathrm{mg})$.

Sugere-se o desenvolvimento de novos trabalhos com a utilização do Bioestimulante Radifarm ${ }^{\circledR}$ no enraizamento de estacas de $H$. marrubioides, testando novas concentrações.

\section{Effect of Extract Nutsedge Plant Growth Regulator on Rooting of Hyptis marrubioides Epl.}

\section{Abstract}

Hyptis marrubioides Epl. (mint-of-field) is a medicinal plant belonging to the family Lamiaceae, known for the presence of volatile oils. There is a trend in the use of growth regulators for rooting when it is necessary to speed up the propagation or in the case of species with roots as difficult in the case of $H$. marrubioides. The objective of this study was to evaluate different concentrations of the extract of tubers of purple nutsedge $(0.0,25.0 \%, 50.0 \%$ and $100.0 \%)$ and Biostimulant Radifarm ${ }^{\circledR}(0.0 \mathrm{~mL}$ and $2.5 \mathrm{~mL}$ ). Two experiments were conducted in a completely randomized design (CRD), the first consisting of six replicates per treatment and five plants per plot and the second with five replications and 10 plants per plot. After 40 days were evaluated root length $(\mathrm{cm})$, root dry weight $(\mathrm{mg})$, number of nodes, number of leaves, number of shoots, shoot length $(\mathrm{cm})$, shoot dry biomass and chlorophyll content. There was significant difference in the treatments with extract only the variable sedge biomass dry matter and observed a dose-dependent relationship. The Biostimulant Radifarm ${ }^{\circledR}$ provided greater number of nodes in herbaceous $H$. marrubioides (6.24) and chlorophyll a (189.4). Regarding root dry biomass, the plant growth regulator promoted an average accumulation of $24.4 \mathrm{mg}$.

Keywords: Mint-of-field. Medicinal plant. Extract sedge. Biostimulating. 


\section{Referências}

ARRUDA, L. A. M.; BARROSI, A. P. O.; ALMEIDA, A. P.; ALVES, A. O.; GALDINO, R. M. N.; XAVIER, A. S. Atividade hormonal do extrato de tiririca na rizogênese de estacas de sapoti. In: JORNADA DE ENSINO, PESQUISA E EXTENSÃO DA UFRPE-JEPEX,9. 2009, Recife. Anais... Recife: UFRPE.

BOTREL, P. P. Influência de genótipos, ambientes de cultivo e variação sazonal no teor e composição química do óleo essencial de Hyptis marrubioides Epling e seu efeito sobre formigas saúva-limão. 2009. 80p. Dissertação (Mestrado em Agronomia/Fitotecnia) - Universidade Federal de Lavras, Lavras, 2009a.

BOTREL, P. P. PINTO, J. E. B. P.; FIGUEIREDO, F. C.; BERTOLUCCI, S. K.; FERRI, P. H. Teor e composição química do óleo essencial de Hyptis marrubioides Epling (Lamiaceae) em diferentes genótipos. Revista Brasileira de Plantas Medicinais, Botucatu, v.11, p.164-169, 2009b.

CASTRO, P. R. C.; VIEIRA, E. L. Aplicações de reguladores vegetais na agricultura tropical. Guaíba, Ed. Agropecuária, 132p. 2001.

CASTRO, P. R. C.; VIEIRA, E. L. Ação de bioestimulante na cultura da soja (Glycinemax (L.) Merril). Stoller do Brasil, Cosmópolis, 73p. 2004.

CORREAA, M. P. Dicionário das plantas úteis do Brasil e das exóticas cultivadas. Rio de Janeiro: Ministério da Agricultura/ IBDF, 1931. 747p.

CUDNEY, D. Nutsedge: history, economy, importance and distribution. In: NUTSEDGE Management Workshop. Riverside: University of California, 1997.

DIAS, J. P. T.; PALANGANA, F. C.; ONO, E. O.; FERREIRA, J.; RODRIGUES, J. D. Bioestimulante e substratos na propagação de amoreira-preta. Revista Tropica: Ciências Agrárias e Biológicas, Maranhão, v.6, n. 3 p.102-110 2012.

FALCÃO, D. Q.; MENEZES, F. S. Revisão etnofarmacológica, farmacológica e química do gênero Hyptis. Revista Brasileira de Farmacognosia, Curitiba, v.84, n.3, p.69-74, 2003.

FALKER AUTOMACAO AGRICOLA Ltda. Manual do medidor eletrônico de teor clorofila: ClorofiLOG / CFL1030). Porto Alegre: Falker Automação Agrícola, 2008. 33p.

FANTI, F. Aplicação de extratos de folhas e de tubérculos de Cyperus rotundusL. (Cyperaceae) e de auxinas sintéticas na estaquia caulinar de Duranta repensL. (Verbenaceae). 2008. 85p. Dissertação (Mestrado em Botância), Universidade Federal do Paraná, Curitiba, PR, 2008.

FERREIRA, D. F. Análises estatísticas por meio do Sisvar para Windows 4.0. In: REUNIÃO ANUAL DE REGIÃO BRASILEIRA DA SOCIEDADE INTERNACIONAL DE BIOMETRIA, 45., 2011, São Carlos. Anais... São Carlos: UFSCar, 200. p.255-258.

HARTMANN, H. T.; KESTER, D. E.; DAVIES JUNIOR, F. T.; GENEVE, R. L. Plant propagation: principles and practices. 7. ed. New Jersey: Prentice Hall, 2002. 880 p.

KLAHOLD, C. A. Resposta da Soja (Glycine Max (L.) Merrill) a ação de bioestimulante. 2005. 37 f. Dissertação (Mestrado em Agronomia)-Universidade Estadual do Oeste do Paraná, Marechal Cândido Rondon. 
MENEZES, F. S. Base química de tendências filogenéticas em Lamiiflorae. 1994. 94p. Dissertação (Mestrado Núcleo de Pesquisas de Produtos Naturais), Universidade Federal do Rio de Janeiro, Rio de Janeiro.

MEYER, S. E. ROSA L. Woody plant seed manual. Washington: USDA Forest Service, 1974. Disponível em: <http://www.wpsm.net/Rosa.pdf>. Acesso em: 01 jul. 2013.

NETO, A. J. A.; SILVA, C. T. A. C. Efeito de diferentes concentrações de extratos aquosos de tiririca (Cyperus rotundus L.) sobre o enraizamento de cana-de-açúcar (Saccharum spp). 2008. Dissertação (Mestrado em Agronomia). Faculdade Assis Gurgacz, Cascavel, PR, 2008.

PIEREZAN, L.; SCALON S. P. Q.; PEREIRA Z. V. Emergência de plântulas e crescimento de mudas de jatobá com uso de bioestimulante e sombreamento. Cerne, Lavras, v.18, n.1, p.127-133, 2012.

PRADO, M. A. O.; FREITAS, S. P.; SUDRÉ, C. P. Efeitos de concentração de AIB e substratos na propagação de alecrim. Horticultura Brasileira. v. 18, 2000, 1041p.

RAVEN, J. A. The transportand function of silicon in plants. Biological Reviews of the Cambridge Philosophical Society, Cambridge. v. 58, n.1, p.179-207, 1983.

RODRIGUES, A. K.; BORSATO, A. V.; AMICI, H. Enraizamento de estacas de Cordia verbenacea DC. tratadas com Cyperus rotundus L. Cadernos de Agroecologia. Campo Grande, v.5, p. 23-28, 2010.

SAleS, J. F.; PINTO, J. E. B. P.; BOTREL, P. P.; OLIVEIRA, C. A. B.; FERRI, P. H.; PAULA, J.R.; SERAPHIN, J. C. Compositions and chemical variability in the essential oil of Hyptis marrubioides Epl. Journal of Essential Oil Research, Carol Stream, v.19, n.6, p.552-556, nov./dec. 2007.

SIMÕES, C. M. O.; SPITZER, V. Famacognosia: da planta ao medicamento. Porto Alegre: UFRGS; Florianópolis: UFSC, 2000.

SILVA C. D. Enraizamento de estacas de pinhão manso (Jatropha curcas L). Monografia (Agronomia) - Faculdade Assis Gurgacz - FAG, Cascavel, PR. 36p, 2007.

SILVA, C. P. Enraizamento de estacas de pinheira (Annona squamosa L.), Gravioleira (Annona muricata L.) e atemoeira (Annona squamosa L. X Annona cherimola L.) Tratadas com Ácido Indolbutírico (IBA) e Ácido Naftalenoacético (NNA) e Bioestimulante. 2008. 154f. Tese (Doutorado) - Faculdade de Ciências Agronômicas da Unesp, Campus Botucatu, Botucatu, 2008.

XAVIER, A. S.; ARRUdA, L. A. M.; BARROS, A. P. O.; ALMEIDA, A. P.; ROCHA, R. B.; ALVES, A. O.; GALDINO, R. M. N. Indução de enraizamento em canela Cinnamomum zeylanicum Blume através do extrato de tiririca. In: JORNADA DE ENSINO, PESQUISA E EXTENSÃO DA UFRPE-JEPEX,9. 2009, Recife. Anais... Recife: UFRPE.

\section{Histórico}

Submetido em: 06/02/2014

Aceito em: 02/10/2014 